Economics Development Analysis Journal

\title{
Kesiapan Penggunaan Uang Elektronik Sebagai Fasilitas Penyaluran Dana Program Keluarga Harapan
}

\author{
Fitria Nur Anggraeni ${ }^{1 凶}$
}

${ }^{1}$ Kementrian Koordinator Bidang Perekonomian Republik Indonesia

\section{Info Artikel}

Sejarah Artikel:

Diterima Oktober 2016

Disetujui Desember 2017

Dipublikasikan Februari

2017

Keywords:

Readiness, Financial

Inclusion, PKH, Emoney

\begin{abstract}
Abstrak
Akses masyarakat terhadap lembaga keuangan merupakan salah satu kunci terwujudnya sistem keuangan yang stabil. Namun data OJK (2015) menunjukan hanya 41\% masyarakat Jawa Tengah yang memiliki akses terhadap lembaga keuangan formal. BAPPENAS, BI dan Kementrian Sosial bekrjasama mengkombinasikan uang elektronik dan telefon genggam dalam penyaluran dana Program Keluarga Harapan untuk meningkatkan keuangan inklusif. Penelitian ini bertujuan untuk mengetahui kesiapan masyarakat, manfaat dan hambatan penggunaan uang elektronik dalam penyaluran dana PKH di Desa Genting, Kecamatan Jambu, Kabupaten Semarang.Penelitian ini menggunakan data primer dengan teknik pengambilan sampel populasi. Teknik pengambilan data primer yang digunakan antara lain kuesioner, Forum Group Discussion, Observasi. Teknik analisis data yang digunakan adalah analisis deskripsi pesentase.Hasil penelitian diperoleh bahwa seluruh responden menyatakan sudah siap menggunakan uang elektronik karena memberikan manfaat efisiensi dan efektifitas serta menjadi jembatan awal bagi masyarakat unbanked untuk masuk kedalam sektor keuangan sedangkan kendala yang masih dihadapi masyarakat belum memiliki pengetahuan mengenai uang elektronik serta masih ada yang belum memiliki telefon genggam. Untuk itulah diperlukan peningkatan literasi keuangan agar program tersebut dapat dilaksanakan.
\end{abstract}

Abstract

Public access to financial institutions is one key to the realization of a stable financial system. But OJK (2015) showed only $41 \%$ of people in Central Java who have access to formal financial institutions. Bappenas, BI and Kementrian Sosial collaboration to combines emoney and mobile phones in the disbursement of funds PKH for increase financial inclusion. This study aims to determine the readiness of the community, benefits and barriers to the use of electronic money in the disbursement of funds CCT Genting Village, District Jambu, Semarang.Penelitian district uses primary data by sampling techniques populations. Primary data collection techniques used include questionnaires, Forum Group Discussion, Observations. Data analysis technique used is pesentase.Hasil description analysis showed that all respondents stated are ready to use electronic money for the benefit of efficiency and effectiveness as well as being a bridgehead for unbanked people to enter into the financial sector, while challenges still faced people had no knowledge about the electronic money and there are those who do not yet have mobile phones. That's necessary to increase financial literacy so that the program can be implemented.

(C) 2017 Universitas Negeri Semarang

${ }^{\bowtie}$ Alamat korespondensi: ISSN 2252-6965

Gedung Ali Wardana, Nomor. 2-4

Jalan Lapangan Banteng Timur, Jakarta

E-mail: Fitria.aang@gmail.com 


\section{PENDAHULUAN}

Keuangan inklusif menurut SNKI (2012) merupakan upaya mewujudkan akses masyarakat terhadap layanan keuangan untuk mengurangi kerentanan dan ketidakmampuan ekonomi serta untuk mengurangi kemiskinan. Kemudahan akses masyarakat terhadap layanan keuangan secara inklusif dimana tidak ada lagi batasan bagi setiap orang untuk mendapatkan akses keuangan secara penuh diharap mampu menciptakan sistem keuangan yang stabil dan optimal sehingga dapat mendorong peningkatan perputaran modal yang nantinya dapat memeratakan modal sebagai upaya penanggulangan kemiskinan dan pemerataan pendapatan dalam masyarakat sehingga dapat mendorong pertumbuhan ekonomi.

Namun saat ini Indonesia masih berada pada tahap keuangan inklusif yang masih rendah. Menurut survei yang dilakukan oleh World Bank ditahun 2014 baru 36\% rumah tangga di Indonesia yang memiliki akses terhadap lembaga keuangan formal sedangkan menurut OJK pada tahun 2015 sebesar 59,7\%, jika dibandingkan dengan Negara-Negara di kawasan ASEAN, angka tersebut masih dibawah Singapore yang mencapai $96 \%$, Malaysia $81 \%$ dan Thailand $78 \%$ (Word Bank, 2014).

Berbagai program dicanangkan oleh TP2NK sebagai upaya peningkatan tingkat keuangan salah satunya adalah program Layanan Keuangan Digital (LKD) melalui Agen LKD sesuai dengan Peraturan Bank Indonesia Nomor 16/8/PBI/2014 mengenai penyelenggaran Layanan Keuangan Digital (LKD) dalam rangka keuangan inklusif melalui Agen LKD. Konsep Layanan Keuangan Digital yang dimaksud berdasarkan Penjelasan Peraturan Bank Indonesia Nomor 16/8/PBI/2014 merupakan kegiatan layanan jasa sistem pembayaran dan keuangan yang bekerjasama dengan pihak ketiga atau yang disebut dengan Agen LKD dengan memanfaatkan teknologi berbasis mobile based mapun web based. Salah satu layanan yang diberikan Agen LKD adalah penyaluran dana Pemerintah kepada masyarakat.

Di Indonesia penggunaan uang elektronik sebagai suatu inovasi dalam sistem pembayaran mendapat respon positif dari masyarakat .Hal tersebut ditunjukan dari penggunaan uang elektonik yang mengalami kenaikan disetiap
tahunnya.Sejak diterbitkan di tahun 2008 sampai dengan tahun 2015. Selain dari sisi pengguna, uang elektronik perupakan peluang dan potensi bagi penyedia layanan uang elektronik, hal tersebut dapat terlihat dari jumlah penyedia layanan uang elektronik baik lembaga perbankan maupun lembaga bukan bank yang telah memperoleh ijin penyelenggaran dari Bank Indonesia yang sampai tahun 2015 sebanyak duapuluh.Uang elektronik berbasis telefon genggam dipilih karena saat ini di 33 Indonesia telepon genggam menjadi unsur tidak terpisahkan dalam kehidupan masyarakat. Data Kementerian Komunikasi dan Informatika dalam BPS (2014) selama periode 2013 hingga 2014 persentase rumah tangga yang memiliki telefon genggam diwilayah perdesaan meningkat dari dari 79,42\% menjadi $81,33 \%$ sedangkan di Provinsi Jawa Tengah juga mengalami peningkatan dari 80,78 menjadi 82,46.

Salah satu bantuan sosial yang diberikan oleh pemerintah adalah Program Keluarga Harapan (PKH). PKH merupakan bantuan sosial yang dijalankan sejak tahun 2007 di bawah komando Kementrian Sosial. PKH ditujukan kepada rumah tangga sangat miskin (RTSM) agar dapat keluar dari garis kemiskinan, tetapi juga memperbaiki taraf hidup dan memastikan generasi berikutnya menyelesaikan pendidikan dasar (Husnaprawira, 2014).

Marmujiono (2015) menyebutkan untuk pengentasan kemiskinan diperlukan pemenuhan hak-hak dasar seperti pendidikan dan akses terhadap layanan keuangan. Saat ini penyaluran dana PKH masih melalui PT. POS . Kedepan Bank Indonesia, BAPPENAS, Kemensos, TNP2K, BRI serta Bank Mandiri bekerjasama untuk menyaluran dana batuan sosial $\mathrm{PKH}$ di Indonesia melalui mekanisme alternatif dengan mobile money yang bekerjasama dengan Agen LKD dalam rangka Keuangan Inklusif serta meningkatkan efektifitas dan efisiensi penyaluran bantuan pemerintah.

Pada tahun 2014 telah dilaksanakan uji coba penyaluran bantuan langsung tunai kepada masyarakat penerima Program Keluarga Harapan melalui pilot project pada empat provinsi di Indonesia yaitu Jakarta, Jawa Barat, Jawa Timur dan NTT dengan karakteristik diwilayah perkotaan. Dalam evaluasinya, Pemerintah berkomitmen memperluas lokasi penyaluran 
bantuan menggunakan uang elektronik pada level yang lebih luas (BAPPENAS,2015) sehingga diperlukan suatu analisis lebih lanjut mengenai kesiapan penggunaan uang elektronik terutama diwilayah dengan karakteristik di perdesaan. Ketidaksiapan masyarakat penerima dana $\mathrm{PKH}$ dalam menggunakan uang elektronik akan menyebabkan program tersebut tidak dapat diimplementasikan secara nasional.

Salah satu perluasan wilayah penggunaan uang elektonik dalam penyaluran dana $\mathrm{PKH}$ adalah Jawa Tengah yang merupakan Provinsi terbesar ketiga di Indonesia. Berdasarkan hasil penelitian oleh Deloitte (2014) tingkat populasi penduduk Jawa Tengah mencapai 32,6 juta jiwa dengan PDRB per kapita yang mencapai 19 juta, sedangakan masyarakat yang belum mengakses perbankan mencapai 14,2 juta jiwa dengan penetrasi telepon genggam (mobile) 91\% dari jumlah penduduk. Menurut OJK (2015) indeks inklusi Jawa Tengah sebesar $42 \%$ dibawah nasional yaitu sebsar 59,7\%. Salah satu penyumbang terbesar kelima PDRB di Provinsi Jawa Tengah adalah Kabupaten Semarang, dengan poulasi yang mencapai 1000,89 ribu jiwa, baru 133.157 jiwa atau setara dengan 13,3\% penduduknya yang sudah memiliki rekening dilembaga perbankan (BPS, 2015).

Keberhasilan Program Keluarga Harapan juga tidak lepas dari peran serta Pendamping PKH. Berdasarkan hasil evaluasi kinerja pendamping tahunan dibawah Kementrian Sosial, Kecamatan Jambu merupakan Kecamatan yang memiliki pedamping terbaik di Kabupaten Semarang pada tahun 2015. Sedangkan Desa Genting dipilih karena berdasarkan data dari Dinas Sosial Kabupaten Semarang tahun 2014, Desa Genting merukapan desa di Kecamatan Jambu dengan jumlah masyarakat penerima PKH tertinggi kedua setelah Desa Bedono yaitu sebanyak 29 orang.

Saat ini, dana PKH disalurkan melalui Kantor Pos yang ada di Desa Jambu namun jarak Desa Genting Desa yang mempunyai jarak paling jauh ke dua yaitu $6,90 \mathrm{~km}$ setelah Desa Gemawang $8,20 \mathrm{~km}$ dengan sarana perekonomian seperti kantor pos, perbankan, pasar, puskemas dan pusat pemerintahan yang ada di Desa Jambu.

Selain itu, Desa Genting juga meniliki karakteristik lokasi yang berbukit dan tidak tersedia transportasi umum serta sarana perbankan dan perekonomian lainnya (BPS,

2015). Berdasarkan karakteristik tersebut,, diharapkan Desa Genting dapat menggambarkan karakteristik desa-desa di wilayah lain.

Untuk itulah diperlukan suatu penelitian mengenai bagaimana kesiapan masyarakat;apamanfaat ekonomi yang diperoleh dan apa hambatan dari penggunaan uang elektronik dalam penyaluran dana $\mathrm{PKH}$. Tujuan dari penelitian ini adalah untuk menganalisis kesiapan masyarakat, manfaat ekonomi yang diperoleh dan hambatan dalam penyaluran dana PKH melalui uang elektronik. keuangan inklusif dapat dilaksanakan sehingga program tersebut dapat diimplementasikan dan dapat berjalan dengan lancar sehingga dapat diperoleh manfaat serta menjadi bahan pertimbangan perencanaan pembangunan dan kebijakan strategis pada sektor keuangan khususnya di bidang financial inclusion.

Penelitian ini juga diharapkan dapat menjadi referensi bagi penelitian yang berkaitan dengan sektor keuangan khususnya dibidang financial inclusion.

\section{METODE PENELITIAN}

Populasi dalam penelitian ini adalah seluruhcpenerima dana $\mathrm{PKH}$ di Desa Genting yang berjumlah 29 (dua puluh sembilan) keluarga sangat miskin. Penelitian ini menggunakan.teknik pengambilan sampel populasi.

Variabel penelitian ini meliputi: kesiapan penggunan, uang elektronik dan keuangan inklusif.Jenis data yang digunakan dalam penelitian ini adalah data primer sebagai data utama dan data sekunder sebagai data pelengkap. Teknik yang digunakan untuk memperoleh data primer antara lain Kuesioner, Forum Group Discussion, dan observasi. Sedangkan data sekunder diperoleh dari beberapa sumber data dan literatur seperti data daei World Bank, BPS, BAPPENAS, TNP2K, OJK.

Metode analisis yang digunakan dalam penelitian ini adalah Analisis Deskriptif Persetase. Analisis persentase merupakan metode analisis data yang digunakan untuk menganalisis data primer yang telah diperoleh melalui kuesioner, tujuannya melakukan perbandingan bagian-bagian kecil terhadap total yang diolah dengan cara frekuensi dari masing-masing variabel dibagi dengan jumlah responden dikali 
100 persen, seperti dikemukan Sudjana (2005)

adalah sebagai berikut:

$\mathrm{P}=\frac{f}{N} \mathrm{x} 100 \%$

Keterangan :

P : Persentase

f : Frekuensi

$\mathrm{N}$ : Jumlah responde

\section{HASIL DAN PEMBAHASAN}

Berdasarkan hasil penelitian dapat digambarkan profil responden bersadarkan usia, pendikan dan pekerjaan, responden yang merupakan masyarakat penerima dana $\mathrm{PKH}$ di Desa Genting didominasi oleh usia produktif dengan tingkat pendidikan yang masih rendah dan pekerjaan responden sebagai Ibu rumah tangga dan Petani seperti yang dijelaskan pada tabel

Tabel 1. Identitas Responden

\begin{tabular}{llll}
\hline & Indikator & Jumlah responden & Persentase \\
\hline Usia (Tahun) & $18-30$ & 2 & $9,1 \%$ \\
& $31-42$ & 9 & $40,9 \%$ \\
& $43-54$ & 11 & $50 \%$ \\
\multirow{5}{*}{ Pendidikan } & $55-62$ & 0 & 0 \\
& $63-79$ & 0 & 0 \\
& Tidak tamat SD & 2 & $9,1 \%$ \\
& Tamat SD & 18 & $81,9 \%$ \\
& Tamat SMP & 1 & $5 \%$ \\
Pekerjaan & Tamat SMA & 1 & $5 \%$ \\
& Perguruan Tinggi & 0 & 0 \\
& Ibu rumah tangga & 8 & $36,36 \%$ \\
& Buruh & 7 & $31,81 \%$ \\
& Petani & 5 & $22,72 \%$ \\
& Wirausaha & 2 & $9,09 \%$ \\
\hline
\end{tabular}

Sumber : Lampiran 9, diolah.

\section{Kesiapan Penggunaan Uang Elektronik}

Berdasarkan hasil penelitian dapat digambarkan pada variabelkesiapan penggunaan uang elektronik padaindikator kepemilikan telefon genggam,inetensitas penggunaan, penggunaan fitur pada telefon genggam, kesiapan dan pendapat masyarakat seperti yang dijelaskan pada Tabel 2 .

Berdasarkan indikator indikator pada variabel kesiapan pada Tabel 4.2 dapat digambarkan bahwa masyarakat penerima dana PKH di Desa Genting sudah dapat dinyatakan siap untuk menggunakan uang elektronik dan menganggap penggunaa uang elektronik mudah namun belum seluruh responden memiliki telefon genggam sebagai media utama uang elektronik.

$82 \%$ responden sudah memiliki telefon genggam dan dari sudah memeliki telefon genggam sebagian besar digunakan selama kurang dari tiga jam dalam satu hari dan menunjukan bahwa kepemilikan telefon genggam digunakan dan fitur yang digunakan oleh seluruh responden adalah SMS dan telefon. Penggunaan fitur pesan singkat dapat mendorong kesiapan penggunaan elektronik.

\section{Manfaat Penggunaan Uang Elektronik dalam Penyaluran Dana PKH}

Berdasarkan hasil penelitian dapat digambarkan pada variabel keuangan inklusif pada indikator jarak, alat transportasi dan biaya yang harus dikeluarkan responden saat mengambil dana $\mathrm{PKH}$ di Kantor Pos serta kepemilikan rekening dilembaga keuangan formal seperti yang dijelaskan pada Tabel 3 . 
Tabel 2. Kesiapan Masyarakat dalam Penggunaan Uang Elektronik

\begin{tabular}{|c|c|c|c|}
\hline \multicolumn{2}{|c|}{ Indikator } & Jumlah responden & \multirow[t]{2}{*}{ Persentase } \\
\hline Kepemilikan Telefon & Sudah memiliki & 18 & \\
\hline \multirow[t]{2}{*}{ ganggam } & Belum memiliki & 4 & $18 \%$ \\
\hline & $<3 \mathrm{Jam}$ & 17 & $94,4 \%$ \\
\hline Intensitas & 4-6 Jam & 1 & $5,6 \%$ \\
\hline penggunaan telefon & 7-8 jam & 0 & 0 \\
\hline \multirow[t]{4}{*}{ genggam } & 9-12 Jam & 0 & 0 \\
\hline & $>12 \mathrm{Jam}$ & 0 & 0 \\
\hline & SMS dan Telefon & 18 & $100 \%$ \\
\hline & $\begin{array}{l}\text { SMS, Telefon dan } \\
\text { Internet (Browsing) }\end{array}$ & 0 & 0 \\
\hline \multicolumn{4}{|l|}{ Penggunaan fitur } \\
\hline & Hiburan & 0 & 0 \\
\hline & Trancaksi kelianoam & 0 & 0 \\
\hline & $\begin{array}{l}\text { Hanya sekedar } \\
\text { memiliki }\end{array}$ & 0 & 0 \\
\hline & Sangat siap & 0 & 0 \\
\hline & Siap & 22 & $100 \%$ \\
\hline \multirow[t]{4}{*}{ Kesiapan masyarakat } & Netral & 0 & 0 \\
\hline & Tidak siap & 0 & 0 \\
\hline & Sangat tidak siap & 0 & 0 \\
\hline & Sangat mudah & 5 & $23 \%$ \\
\hline \multirow{4}{*}{$\begin{array}{l}\text { Pendapat masyarakat } \\
\text { tentang penggunaan } \\
\text { uang elektronik }\end{array}$} & Mudah & 15 & $68 \%$ \\
\hline & Netral & 2 & $9 \%$ \\
\hline & Tidak siap & 0 & 0 \\
\hline & Sangat tidak siap & 0 & 0 \\
\hline
\end{tabular}

Sumber : Lampiran 9, diolah.

\section{Manfaat Penggunaan Uang Elektronik dalam Penyaluran Dana PKH}

Berdasarkan hasil penelitian dapat digambarkan pada variabel keuangan inklusif pada indikator jarak, alat transportasi dan biaya yang harus dikeluarkan responden saat mengambil dana PKH di Kantor Pos serta kepemilikan rekening dilembaga keuangan formal seperti yang dijelaskan pada Tabel 3 .

Pada tabel 3 tersebut dapat dinyatakan bahwa sebagian besar responden harus menempuh jarak yang cukup jauh serta mengeluarkan biaya transportasi serta sebagian besar responden belum memiliki rekening dilembaga keuangan formal.Seperti yang terlah diungkapkan oleh Wahid (2015) dalam teori perilaku masyarakat (firm behaviour theory) skema penggunaan uang elektronik yang bekerjasama dengan agen LKD dalam rangka keuangan inklusif dapat memberikan dampak efisiensi dan efektifitas. Dampak efektifitas dapat diperoleh dari skema tersebut adalah masyarakat lebih dekat saat mengambil dana PKH karena dapat dilakukan di agen LKD terdekat dengan tempat tinggal dan tidak harus ke Kantor Pos. Sedangkan manfaat dari segi efisiensi, skema tersebut dapat memangkas biaya yang dikeluarkan untuk mengambil dana PKH.

Selain itu dengan adaya Agen LKD, masyarakat tidak lagi dibatasi keberadaan bank atau ATM secara fisik. Masyarakat dapat mengambil dana PKH yang disalurkan dengan mudah tanpa ada batasan tempat dan waktu pengambilan karena dengan uang elektronik, dana PKH dapat diambil sewaktu-waktu dan tidak perlu mengantre sehingga meningkatkan keamanan dan kenyamanan. Uang elektronik juga akan meningkatkan akuntabilitas karena dana bantuan dapat dikirim langsung ke rekening pribadi dan menimalisir ruang untuk 
pungutan liar. Uang elektronik juga menjadi jembatan awal masyarakat dapat meregristrasi database untuk membuka rekening ke dalam lembaga keuangan formal dan mengakses layanan dalam lembaga keuangan.
Kombinasi uang elektronik dan telefon genggam memudahkan masyarakat untuk regristrasi karena nomor telefon yang digunakan dalam telefon genggam sekaligus sebagai nomor rekening.

Tabel 3. Jarak, Alat Transportasi, Biaya yang Dikeluarkan saat Pengambilan Dana PKH dan Kepemilikan Rekening di Lembaga Keuangan

\begin{tabular}{|c|c|c|c|}
\hline \multicolumn{2}{|c|}{ Indikator } & \multirow{2}{*}{$\begin{array}{c}\text { Jumlah } \\
\text { Responden }\end{array}$} & \multirow[t]{2}{*}{ Persentase (\%) } \\
\hline & & & \\
\hline \multirow[t]{5}{*}{ Jarak (menit) } & $<15$ & 3 & 13.63 \\
\hline & $15-30$ & 0 & 0 \\
\hline & $30-45$ & 8 & 36.36 \\
\hline & $45-60$ & 8 & 36.36 \\
\hline & $>60$ & 2 & 9.09 \\
\hline \multirow[t]{5}{*}{ Alat Transportasi } & Jalan kaki & 1 & 4.5 \\
\hline & Sepeda & 0 & 0 \\
\hline & Sepeda Motor & 21 & 95.5 \\
\hline & $\begin{array}{l}\text { Angkutan } \\
\text { umum }\end{array}$ & 0 & 0 \\
\hline & Mobil & 0 & 0 \\
\hline \multirow{5}{*}{$\begin{array}{l}\text { Biaya yang dikeluarkan } \\
\text { (ribu rupiah) }\end{array}$} & $<5$ & 0 & 0 \\
\hline & $5-10$ & 1 & 4.5 \\
\hline & $11-15$ & 4 & 18.1 \\
\hline & $16-20$ & 14 & 63.63 \\
\hline & $>20$ & 3 & 13.6 \\
\hline \multirow{2}{*}{$\begin{array}{l}\text { Kepemilikan Rekening di } \\
\text { Lembaga Keuangan }\end{array}$} & Sudah & 8 & 36.4 \\
\hline & Belum & 14 & 63.6 \\
\hline
\end{tabular}

Sumber: Lampiran 9, diolah

Pada tabel 1.3 tersebut dapat dinyatakan bahwa sebagian besar responden harus menempuh jarak yang cukup jauh serta mengeluarkan biaya transportasi serta sebagian besar responden belum memiliki rekening dilembaga keuangan formal.

Seperti yang terlah diungkapkan oleh Wahid (2015) dalam teori perilaku masyarakat (firm behaviour theory) skema penggunaan uang elektronik yang bekerjasama dengan agen LKD dalam rangka keuangan inklusif dapat memberikan dampak efisiensi dan efektifitas.

Dampak efektifitas dapat diperoleh dari skema tersebut adalah masyarakat lebih dekat saat mengambil dana PKH karena dapat dilakukan di agen LKD terdekat dengan tempat tinggal dan tidak harus ke Kantor Pos. Sedangkan manfaat dari segi efisiensi, skema tersebut dapat memangkas biaya yang dikeluarkan untuk mengambil dana PKH.

Selain itu dengan adaya Agen LKD, masyarakat tidak lagi dibatasi keberadaan bank atau ATM secara fisik.

Masyarakat dapat mengambil dana $\mathrm{PKH}$ yang disalurkan dengan mudah tanpa ada batasan tempat dan waktu pengambilan karena dengan uang elektronik, dana PKH dapat diambil sewaktu-waktu dan tidak perlu mengantre sehingga meningkatkan keamanan dan kenyamanan.

Uang elektronik juga akan meningkatkan akuntabilitas karena dana bantuan dapat dikirim langsung ke rekening pribadi dan menimalisir ruang untuk pungutan liar.

Uang elektronik juga menjadi jembatan awal masyarakat dapat meregristrasi database 
untuk membuka rekening ke dalam lembaga keuangan formal dan mengakses layanan dalam lembaga keuangan. Kombinasi uang elektronik dan telefon genggam memudahkan masyarakat untuk regristrasi karena nomor telefon yang digunakan dalam telefon genggam sekaligus sebagai nomor rekening.
Berdasarkan hasil penelitian dapat digambarkan variabeluang elektronik bersadarkan indikator masyarakat mengenal uang elektronik, gambaran pertama uang elektronik dan pengetahuan masyarakat terhadap rencana penggunaan uang elektronik dalam penyaluran dana PKH dijelaskan pada Tabel 1.4 berikut.

Tabel 4. Pengetahuan Masyarakat tentang Uang Elektronik

\begin{tabular}{|c|c|c|c|}
\hline Indikator & & Jumlah & Persentase (\%) \\
\hline \multicolumn{4}{|c|}{ Responden } \\
\hline Masyarakat & Sudah & 0 & 0 \\
\hline Mengenal & Belum & 22 & $100 \%$ \\
\hline \multicolumn{4}{|l|}{ Elektronik } \\
\hline & ATM & 5 & $23 \%$ \\
\hline & Transfer Uang & 11 & $50 \%$ \\
\hline \multirow{4}{*}{$\begin{array}{l}\text { Gambaran Pertama Uang } \\
\text { Elektronik }\end{array}$} & Penarikan & 1 & $4 \%$ \\
\hline & Uang & & \\
\hline & Kode PIN & 0 & 0 \\
\hline & Tidak mengerti & 5 & $23 \%$ \\
\hline $\begin{array}{l}\text { Pengetahuan tentang } \\
\text { rencana penggunaan uang } \\
\text { elektronik dalan } \\
\text { Dana PKH }\end{array}$ & $\begin{array}{l}\text { Sudah } \\
\text { mengetahui }\end{array}$ & 0 & 0 \\
\hline
\end{tabular}

Belum adanya pengetahuan dari masyarakat terkait penggunaan uang elektonik serta ditambah dengan profil responden yang masih memiliki tingkat pendidikan rendah menjadi penghambat pelakasaan program.Pengetahuan masyarakat dalam menggunakan uang elektronik sangat diperlukan agar program dapat berjalan lancar sehingga dapat diperoleh. Seperti yang telah diungkapkan oleh Wahid (2015) salah satu tahap untuk mewujudkan keuangan inklusif adalah literasi atau kemampuan untuk memahami produk dan profil keuangan yang salah satunya adalah penggunaan uang elektronik berbasis telefon genggam untuk tansaksi transfer pemerintah ke masyarakat. Diperlukan penyusunan program sosialisasi untuk pengenalan uang elektronik kepada masyarakat. Sedangkan untuk meningkatkan tingkat literasi atau pengetahuaan terhadap layanan keuangan diperlukan program edukasi penggunaan layanan uang elektronik kepada masyarakat baik melalui media cetak seperti majalah, buku, koran serta melalui media elektronik seperti iklan layanan masyarakat dan video edukasi.

Selain hamabatan dari segi pengetahuan, hambatan lain adalah masih ada masyarakat yang belum memiliki telefon genggam sebagai media utama penggunaan uang elektronik yaitu masihterdapat $19 \%$ responden yang belum memiliki telefon genggam. Disisi lain masyarakat sudah menyatakan kesiapannya dalam menggunakan uang elektronik. Hal tersebut dapat mengganggu kelancaran pelaksanaan pembayaran dana PKH melalui uang elektronik. Dari hambatan tersebut diharapkan, rencana penggunaan uang elektronik dalam penyaluran dana PKH dapat dikontrol dan dievaluasi kembali serta dibutuhkan koordinasi antar pihak agar program dilanjutkan sehingga strategi penggunaan uang elektronik dalam penyaluran dana $\mathrm{PKH}$ yang bertujuan untuk meningkatkan keuangan inklusif dapat segera di implementasikan di seluruh wilayah Indonesia. Terlebih masyarakat maupun pihak pihak terkait seperti Bank BRI sudah menyatakan kesiapannya dalam menggunakan uang elektronik.Selain hamabatan dari segi pengetahuan, hambatan lain adalah masih ada masyarakat yang belum memiliki telefon genggam sebagai media utama penggunaan uang elektronik yaitu masihterdapat $19 \%$ responden yang belum memiliki telefon genggam. Disisi lain masyarakat sudah menyatakan kesiapannya dalam menggunakan 
uang elektronik. Hal tersebut dapat mengganggu kelancaran pelaksanaan pembayaran dana $\mathrm{PKH}$ melalui uang elektronik.

Dari hambatan tersebut diharapkan, rencana penggunaan uang elektronik dalam penyaluran dana $\mathrm{PKH}$ dapat dikontrol dan dievaluasi kembali serta dibutuhkan koordinasi antar pihak agar program dilanjutkan sehingga strategi penggunaan uang elektronik dalam penyaluran dana $\mathrm{PKH}$ yang bertujuan untuk meningkatkan keuangan inklusif dapat segera di implementasikan di seluruh wilayah Indonesia. Terlebih masyarakat maupun pihak pihak terkait seperti Bank BRI sudah menyatakan kesiapannya dalam menggunakan uang elektronik.

\section{SIMPULAN}

Berdasarkan penelitian yang telah dilakukan oleh penulis, maka diperoleh beberapa simpulan bahwa seluruh masyarakat penerima dana $\mathrm{PKH}$ di Desa Genting sudah dapat dinyatakan siap untuk menggunakan uang elektronik dalam penyaluran dana PKH dan diharapkan program tersebut dapat di implementasikan segera. Selain masyarakat, pemerintah daerah dan perbankan penyelenggara juga siap mendukung terlaksananya program. Manfaat ekonomi yang diperoleh dari penggunaan uang elektronik dalam penyaluran dana $\mathrm{PKH}$ adalah efektifitas dan efiasiensi dari segi biaya transportasi, jarak tempuh lebih dekat, notifikasi penyeluran dana dapat lebih cepat, uang dapat diambil sewaktu-waktu, kemudahan transfer, serta menjadi jembatan awal masyarakat untuk masuk ke dalam sektor keuangan dengan kepemilikan rekening di lembaga keuangan formal yang menjadipintu masuk untuk mengakses layanan keuangan seperti tabungan dan kredit.

Kendala penggunaan uang elektronik dalam penyaluran dana $\mathrm{PKH}$ adalah masih ada masyarakat yang belum memiliki telefon genggam dan masyarakat yang belum memiliki pengetahuan mengenai uang elektronik.

\section{DAFTAR PUSTAKA}

BPS kabupaten Semarang . 2014. Kecamatan Jambu dalamAngka 2014. Ungaran : Badan Pusat Statistik

Harris, Hezlin., Guru, Balachander Krishnan., Avvari, Mohan V. 2011. Evidence of Firms' Perceptions Toward Electronic Payment Systems (EPS) in Malaysia International
Journal of Business and Information; Sansia Vol.

6, Iss. 2, 226-245.

Hawk, Stephen. 2004. A Comparison of B2C ECommerce in Developing Countries. Electronic Commerce Research. Vol. 4 (3) pp. 181-199

Hidayati, Siti, dkk. 2006. Operasional E-Money. Jakarta: Bank Indonesia

Husnaprawira, Rangga. 2014. Pelatihan Melek Keuangan Berbasis Komunitas Bagi Anggota

Program Keluarga Harapan Sebagai Langkah Mandiri Penanggulangan Kemiskinan. Karya Tulis Ilmiah Mahasiswa Berprestasi. Depok: Universitas Indonesia

Irmawati, S., Damelia, D., \& Puspita, D. (2013). Model Inklusi Keuangan Pada Umkm Berbasis Pedesaan. Jejak: Jurnal Ekonomi Dan Kebijakan, 6(2).

doi:http://dx.doi.org/10.15294/jejak.v6i2. 3885

Marmujiono, S. (2015). Analisis Faktor-Faktor Yang Mempengaruhi Tingkat Kemiskinan Dan Strategi Pengentasan Kemiskinan Di Kab. Brebes Tahun 2009-2011. Economics Development Analysis Journal, 3(4). doi:http://dx.doi.org/10.15294/edaj.v3i4. 3221

Tarunajaya, Chairil. 2015. The future is now: Digital Financial Services in Indonesia . Jakarta: Delloite

Tim inisiatif Bank Indonesia. 2006. Upaya Meningkatkan Penggunaan Alat Pembayaran Non Tunai melalui Pengembangan E-Money (Working Paper). Jakarta: Bank Indonesia

Peraturan Bank Indonesia Nomor 16/12/DPAU mengenai Penyelenggaran Layanan Keuangan Digital Dalam Rangka Keuangan Inklusif Melalui Agen Layanan Keuangan Digital Individu Lembaran Negara Republik Indonesia tahun 2014 Nomor 69. 2014. Jakarta

Purcell, Fuatai., Toland, Janet. 2004. Electronic Commerce for the South Pacific: A Review of E-Readiness. Electronic Commerce Research Vol. 4 (3) pp 241-262.

Wahid, Nurson. 2015. Keuangan Inklusif: Membongkar Hegemoni Keuangan. Jakarta: PT Gramedia. 